\title{
Research on Financial Mechanism in Precise Poverty Alleviation
}

\author{
Jiang Yao, Xu Danni \\ School of Management, Sichuan Agricultural University, Chengdu Sichuan 611130, China \\ School of Public Administration, Southwestern University of Finance and Economics, Chengdu \\ Sichuan 611130, China
}

Keywords: precise poverty alleviation; evaluation and innovation of finance poverty alleviation mechanism

\begin{abstract}
Poverty alleviation is the necessary requirement of the common prosperity of socialism, which is the inherent requirement of achieving a well-off society in an all-round way in 2020, and precise poverty alleviation is still a necessary measurement for high-efficiency poverty alleviation. With the development of the macro policy, the precise poverty alleviation has been putting on the new stage. Finance is an important hand to solve the problem of rural poverty. At present stage, the supply of financial funds is insufficient, and the funds circulation is unobstructed. This paper evaluates the impacts of the current financial mechanism in precise poverty alleviation, and it puts forward some relevant measures and suggestions on strengthening the innovation between finance poverty alleviation mechanism and precise poverty alleviation.
\end{abstract}

\section{The Process of Precise Poverty Alleviation in China}

\subsection{Macroscopic propulsion}

On January 25, 2014, Opinions on the Solid Promotion of Innovative Mechanisms into the Work of Poverty Alleviation and Development in Rural Areas was issued, which was another programmatic document after the implementation of the Outline of China's Rural Poverty Alleviation and Development Program in 2011-2020. This document puts forward requirements for improving financial services mechanism, highlighting the innovation, concentrating on solving crucial problems, which will be more congruously and efficiently in implementing the central government's strategy for poverty alleviation. It has made arrangements for the next step in the fight against poverty and issued a mobilization order in the new era. Finance is a crucial department of the funds supply, and the work of helping the poor is inseparable from the department of finance. Therefore, the financial mechanism has a great practical significance in rural poverty alleviation.

\subsection{The Necessity of Using Financial Mechanism in Precise Poverty Alleviation}

Since the reform and opening up in 1978, China's poverty alleviation work has made remarkable achievements. The number of extremely poor people in rural areas has decreased from 250 million 
in 1978 years to about 20 million in 2012, and the per capita net income of peasant households also increased from 2475.6 yuan to 7916.6 yuan in 2012.

With the development of poverty alleviation practice, the work of poverty alleviation in our country has appeared some new characteristics, also has faced the new challenges. Until now, the investment of financial funds in our country has never found an optimal scale: in the total amount of financial funds for poverty alleviation is increasing, but the share of fiscal expenditure is highly volatile. In terms of the poverty alleviation structure, poverty alleviation in key counties is more likely to be emphasized, and non-key poverty alleviation in counties or towns may be neglected. On the object of poverty alleviation, the enterprise is the key object of poverty alleviation. At a time when there are a large number of poor people and new challenges in financial investment, for which it is necessary to carry out precise poverty alleviation policy and to use the financial mechanism.

Funds are the core of supporting precise poverty alleviation. At the present stage, the financial funds are inclined to the precise poverty alleviation, but there are still some problems, such as the shortage of funds, the imbalance of structure and the proportion of investment, etc. In the process of the precise poverty alleviation, it is necessary to effectively allocate the capital, to avoid the outflowing of funds and forming "fund low-lying land" in rural areas. In addition to financial and credit funds for poverty alleviation, financial poverty alleviation funds themselves cannot flow directly into the hands of farmers in the form of cash. They all need to link up with farmers' needs in the form of financial poverty alleviation projects and others. In this way, it is necessary to provide financial support and supplement from rural finance and credit objectively, to fill the farmers' fund demand in time, and to form a virtuous circle of rural capital flow.

\section{Evaluation and Innovation of Financial Mechanism in Precise Poverty Alleviation}

\subsection{Actuality Evaluation}

The financial mechanism has not been deeply combined in the precise poverty alleviation. But the allocation of financial funds for poverty alleviation and the issuance of credit funds have not been combined at present. With the imperfect financial and credit system in rural areas, the high non-performing loan rate and the low recovery rate of funds in rural areas, it is very difficult for poor households to get the support of credit funds. For banks, financial poverty alleviation is not their main profit direction. Under the influence of potential profits, more credit funds have gone to other profitable customers.

Financial system is too old, difficult to break through, it also lacks the hematopoietic function. In the process of precision poverty alleviation, because of many years of solid rural poverty alleviation, a series of antipoverty measurements and ideas of poverty alleviation are deeply rooted in the hearts of the people. While the socialist market economy is developing, the financial system cannot be better innovated. In the past, the government released funds to the poor households, and used funds in infrastructure construction, resulting in a shortage of funds, the growth of corruption and the investment plan is out of step with the actual construction project. The essence of financial poverty alleviation lies in the hematopoiesis and the return of capital. If the credit fund is not in place, the financial hematopoietic function will be seriously lacking.

\subsection{Innovation of Financial Mechanism in Precise Poverty Alleviation}

Firstly, strengthen the combination of financial mechanism, and deepen the precise poverty alleviation. The aim of financial mechanism implementation is to achieve precise poverty alleviation. At present, while the current financial funds are constantly slanting toward poverty alleviation, they should also tilt to the small and medium-sized rural financial institutions, to 
improve the credit system and loan system of the small and medium-sized rural financial institutions. Bring into play to the regional and scale advantages of the small and medium-sized rural financial institutions and realize the hematopoietic function of financial system.

Secondly, adopting the method of making use of financial funds in a paid use pilot way, rolling to raise the efficiency of fund utilization. This part of the financial funds can be obtained from the way of financial hematopoiesis. There is a "strange circle of funds" in the government undefined poverty alleviation. When the government allocates more money in poverty alleviation, the living conditions of the poor households will be improved, and when there is less allocated, their life is once again in trouble. The reason lies in the ideological backwardness of poor households. While solving poverty among poor households, it is necessary to improve the production enthusiasm, because it is the development of self-productivity of poor households, and it also meets the requirement of sustainability of accurate poverty alleviation.

Lastly, we should improve the conception of poverty alleviation in the outdated financial mechanism and innovate the use of financial tools and financial instruments in the development of the market economy. For example, we can carry out the quantitative reform of the capital stock right of the financial supporting agriculture, to effectively promote the process of precise poverty alleviation and increase farmers' property income. The government can innovate the supporting mechanism of science and technology, select and dispatch science and technology talents to the poor district to carry out technical guidance. Carrying out rural contracted management right, forest right and other rural property right mortgage guarantee financing, actively implement poverty alleviation micro-credit, issue loans to poor households.

\section{References}

[1] Wang Yangkai, Wang Xiaohan. Research on the Cooperative Poverty Alleviation Mechanism of Finance [J]. Economic Trade of Times.2014 (06)

[2] Lu Mingning. Rural Poverty Problems and Countermeasures: An Empirical Analysis of Liangshan Prefecture, Sichuan Province [J]. Rural Economy.2012 (11)

[3] Tian Yingying. Research on the Precision of Financial Poverty Alleviation in Baoding City [J]. Cooperative Economy and Science and Technology.2016 (06)

[4] Li Ningli, Zhou Can, Wang Dingxiang. China's Rural Poverty Alleviation Financial System: Evolution, Experience and Trend [J]. Rural Economy.2018 (01) 